\title{
MANAGING RURAL DEVELOPMENT
}

\section{Robert Chambers*}

This research, which was mainly concerned with the design and testing of management procedures for use by government servants in rural areas in Kenya, was carried out during 1971-73 in collaboration with Deryke Belshaw of the Overseas Development Group of the University of Norwich. It was linked with the Kenya government's Special Rural Development Programme (SRDP), an experimental programme undertaken in six parts of Kenya with objectives which included raising rural incomes and employment opportunities and sharpening the effectiveness of the government machine in rural areas.

At a late stage in the research, its rationale was summarised as follows:

"It is a commonplace that executive capacity is a constraint on rural development in developing countries. Traditional prescriptions for increasing such capacity have been quantitative (more manpower, more technical assistance, more finance) and usually qualitative only through an emphasis on the importance of training. Where administrative reform has been undertaken, attention has tended to focus on organisation and procedures in headquarters and on the reduction of corruption. Valuable though these approaches may be, the working hypothesis of the research ... is that a key point of leverage in improving the effectiveness of rural development programmes in general and of agricultural extension in particular is the devising and introduction of planning and management techniques and procedures for the lower levels of administration".

There is a good deal of ex post rationalisation in this statement. The

* Robert Chambers was funded first by the Rockefeller Foundation, then by himself, and finally by ODA through IDS at the University of Sussex for a six months finishing off period. Local institutional support in Kenya was provided by the IDS University of Nairobi, and the East African Staff College. The author is grateful to these institutions for their support and to Deryke Belshaw, other colleagues and many Kenya government servants for their collaboration. 
research had come about from a flow of pressures, interests and commitments. Had there been a rigid formal requirement at an early stage for a conventional research proposal it might not have been possible to follow the leads which presented themselves. Not much research has or perhaps should have this degree of freedom; but in this case, involving relationships with a rapidly developing and changing development programme and exploring a field which was the province of no discipline, it was a great help not to be constrained by precise statements of what we were aiming to do, or how we were going to try to do it.

What happened was that the Institute for Development Studies of the University of Nairobi agreed to provide evaluation for the SRDP. The SRDP headquarters officials were very heavily engaged in getting the programme off the ground and sought advice from the IDS Nairobi in the design of reporting procedures for local-level staff who were working on the programme. As soon as we became involved and began to prepare a reporting system we realised the need for this to fit into a wider framework. We were drawn backwards from reporting into implementation, programming, budgeting and plan formulation and we found ourselves designing and testing a series of management procedures for government staff at the local rural levels which covered much more than just reporting.

At the same time we began to see more clearly what now looks more obvious: that there was a misallocation of administrative and planning resources in East Africa, with too much attention paid to plan formulation and budgeting and too little to programming and implementation (the many mimeographed volumes of unimplemented district plans gathering dust on the shelves of government offices were evidence enough of this); that capital projects and the capital budget received disproportionate attention from planners and administrators to the neglect of the often much larger resources committed more or less automatically to recurrent operations and programmes; and that government field staff were a major and expensive but underestimated and underutilised national resource, operating at levels far below their potential. To correct these imbalances and exploit this potential, management procedures appeared to offer a powerful point of entry. But no social scientists 
in East Africa were, as far as we knew, concerned with the study and improvement of government procedures, an extraordinary research gap. Further, what literature there was on the subject was either at the level of departmental instructions, circulars and rule books, or derived from and couched in the slightly esoteric concepts and language of engineering systems analysis (for example Kulp, 1971. See also Chege, 1973 for a lively critique). Even within governments, the design of procedures and the introduction of management techniques were not usually recognised subjects of major concern (this was before the Tanzanian decentralisation). Indeed, government procedures, far from being pilot tested, evaluated, modified, and then replicated gradually, as were some other approaches to rural development, tended to the contrary to be thought up in a hurry by busy civil servants, incorporated in authoritative circulars, and issued universally and adopted at once. These various insights, if that is not too pretentious a word for what now seems so obvious, encouraged us to pursue the leads which opened up, and to adopt an experimental approach to designing and testing procedures with government staff at the local rural level, concentrating on those activities, particularly programming and implementation, which had previously been relatively neglected.

In designing procedures we drew on several sources of ideas including Management by objectives, the Malaysian red book system, critical path method, and procedures which were already in use in the government. For various reasons we rejected many elements in these sources, adopting and adapting only those which seemed relevant. We found a simple form of systems analysis helpful as a device for sorting out and classifying procedures. Using this, Belshaw was responsible for the useful step of organising discussion and experiment around six clusters of procedures, described as:

Programming and Implementation

Field Staff Management

Local Participation

Evaluation

Rural Research and Development

Plan Formulation

Placing these in boxes and linking them with lines made it easier to identify and discuss the points at which the benefits from procedural 
innovation might give the best returns to effort. We came to place plan formulation last because of the common experience of plan formulation without implementation, and even of pathological data collection without plan formulation. Although work was done on evaluation, on rural research and development, and on plan formulation, we concentrated at first on the neglected areas of programming and implementation, and field staff management.

\section{Programming and Implementation}

The Programming and Implementation Manager (PIM) system was developed in collaboration with the government staff who were to use it. It was modified and simplified several times. It had three main components.

The first was an annual programming exercise at which the staff involved in a programme (such as dips, crop extension, road construction, credit, family planning, land consolidation, or ranch development) met and jointly followed a procedure in which they identified and agreed on the objectives of the programme, the operations to be carried out, who was responsible for what, the resources required, timings and deadlines, and what constituted completion of each operation. The discussion often made use of a blackboard which all participants could see, and the agreement reached was recorded on forms and charts which could be referred to later in the course of implementation. The meeting required staff of different departments, and sometimes of different levels in the same department, to come together. The first year's experience showed dramatically that the biggest bottleneck in rural development was fund releases in Nairobi, and in subsequent years the headquarters ministry officer responsible for funds attended the meetings and accepted commitments to deadlines in the presence of his field colleagues.

The second component was a monthly meeting at which progress was reviewed against the programme as drawn up at the annual programming exercise. Problems were identified, co-operation encouraged, and remedial action sought.

The third component was a monthly report which was prepared after 
the meeting and sent simultaneously to government staff at different levels and in different departments. The layout of the report was unconventional, focusing on timeliness of operations, action required, and who was to take it.

There were several evaluations of the PIM system (including Chabala et al, 1973 and IDS Nairobi, 1973). Opinions differed about the desirable frequency and content of meetings and reports. At one stage in one area the reporting burden was excessive because of the experimental treatment of incorporating every rural development project into the system; the lesson was that only priority projects and those which involved several departments should be included. Like any system PIM had its shortcomings and its costs. But it was generally agreed that it did have some substantial advantages. Among others, departmentalism was reduced, needs and problems were identified in advance, meetings were tied down to discussions of practical detail, those responsible for bottlenecks and delays were shown up, and field staff were provided with a legitimate means of communicating their problems to those high up in the hierarchy. An annual implementation review, based on the monthly reports and the experience of a year of implementation, also meant that lessons were systematically learned and that senior officers in headquarters were made more aware of problems in the field.

While modifications would be needed for each administrative environment, some of the principles and elements in these procedures (described in much more detail in Chambers and Belshaw, 1973, chapter 2) might well be applied with good results in other countries.

\section{Field Staff Management}

Management procedures for field staff were developed in collaboration with the agricultural staff (both crops and livestock staff) of one of the SRDP Divisions, Mbere. Devising effective systems proved much harder than we expected and over a period of about 18 months many changes were introduced. The main thrust was an attempt to improve performance through work planning and closer supervision. Two systems were evolved - one based on work planning by partially self-set targets and used by the better-educated 
crops staff whose tasks were more complicated and less routine; and the other based on work planning on a daily diary basis, used by livestock staff who were less well educated and whose work was simpler and more routine.

Both relied on a monthly meeting of the supervisor with his staff. At this meeting, each staff member was first debriefed about his previous month's work, comparing what he had done with what he had agreed to do at the previous month's meeting. Then the next month's programme was discussed. Finally a work programme was drawn up with participation by the staff in suggesting what they should do and what targets they should aim to achieve. (The two systems are described and discussed in more detail in Chambers and Belshaw, 1973, chapter 3. Other parts of that paper discuss local participation, rural research and development, evaluation, and plan formation).

\section{Principles in the Design of Procedures}

The details of some of the procedures which were developed may provide ideas which can be used by others elsewhere. But perhaps more important are the principles which underlie them and the lessons of the more obvious of the mistakes which we made. In terse summary some of these are:

$\begin{array}{ll}- & \text { seeking sophistication in simplicity } \\ - & \text { adopting a pilot approach at first } \\ \text { - } & \text { treating field staff as a finite and scarce resource } \\ \text { - } & \text { appreciating the field-staff-eye view of the world } \\ \text { - } & \begin{array}{l}\text { involving participating staff in the design and } \\ \text { evaluation of procedures }\end{array} \\ \text { - } & \text { keeping meetings and reports short and functional } \\ \text { - } & \text { using joint programming and joint target-setting } \\ \text { - } & \text { subsuming or abolishing old procedures } \\ \text { - } & \text { restraining demands for information. }\end{array}$

Perhaps surprisingly, this last may well be the most important, apart from the first which has an overarching nature. The biggest danger in designing procedures is intellectual perfectionism and the demand for excessive amounts of data that goes with it. One of the most terrible fates is for field staff to become linked to a voracious computer with a ravenous appetite for information. It is far, far easier to make a 
case for more information than to make a case for less; and far easier to introduce a new reporting requirement than to abolish one. The principle of optimal ignorance, firmly grounded in the realisation that information has costs, is extraordinarily difficult to apply. But if it is not applied, then the result is liable to be the submergence of field staff under a sea of paper, tying them to their offices, and making them clerks, accountants, and eventually perforce writers of fiction, instead of field workers. ${ }^{1}$

\section{The Future}

The experience of this research seems to strengthen the case for more attention to management procedures in rural development, but whether or not they become a focus must depend upon the interest which is shown in them in the countries concerned. There are obvious dangers - of excessive use of systems language, of the computerisation of programme and project monitoring, of management consultants who come and go and leave behind them (did we?) unwieldy or inappropriate modes of operation, of the creation of routines which quickly rigidify into mindless rituals, of subversion of reporting through the invention or distortion of data. There may well be a case for the selective use of some imported expertise but rural development may be par excellence a field in which the details (not necessarily the basic principles) of management cannot be imported without bad effects. It is sometimes difficult to avoid the temptations of systems language, or the attractions of the latest management gimmicks. But what is most needed is the building up and diffusion of a body of local experience among local practitioners in rural development, cross-fertilised with the critical insights of the appropriate social sciences. The danger has been that social scientists will regard management and procedures as dull and outside their proper fields. Yet sociologists and students of public administration in particular are well placed to contribute through the collection and organisation of experience, through building up repertoires of techniques, through their awareness and

1 A colleague in a South Asian country was recently told by an agricultural extension worker that he had to submit 29 reports and returns a month. The number had increased recently because of a food crisis and a food production drive. 
identification of unintended effects, and through their capacity for research and development work and for independent evaluation. One implication is that management procedures should receive attention in university courses and that the evaluation of procedures should be a regular part of student fieldwork, as has already happened in the University of Nairobi (for an example see Chabala et al, 1973). In the longer term this would mean that the graduates who become civil servants would be better equipped to design procedures themselves, more aware of the unintended effects which are so common, and better able to contribute to a national and international body of experience.

An immediate application to be explored is the potential of specially designed procedures for directing programmes more accurately to new target groups. The notorious tendency for agricultural extension staff to visit and favour the larger and weal thier farmers is the most obvious case in point. In trying to reach poorer and less influential farmers, appropriate procedures may have a crucial part to play. At this time, too, when land reform programmes are so often regarded with despair and cynicism, it may be worth asking to what extent new management procedures could make them more effective. But whether these opportunities are explored, and whether, if explored, the results are applied, depend largely on national policy and above all on political will. Perhaps it is no coincidence that among East African countries it has been Tanzania, with its concern for equity, which has shown most interest in the design and implementation of management procedures.

\section{References and Some Relevant Documents}

Belshaw, Deryke and Robert Chambers, 1971 "Programming, Operational Control and Evaluation for Rural Development Plans", Staff Paper no. 111, IDS Nairobi

Belshaw, Deryke and Robert Chambers, 1973a "A Management

Systems Approach to Rural Development", Discussion Paper no. 161, IDS Nairobi

Belshaw, Deryke and Robert Chambers, 1973b "PIM: A Practical

Management System for Implementing Rural Development

Programmes and Projects", Discussion Paper no. 162, IDS

Nairobi 
Chabala, H.A., David H. Kiiru, Solomon W. Mukuna and David K. Leonard, 1973 "An Evaluation of the Programming and Implementation Management (PIM) System", Working Paper no. 89, IDS Nairobi

Chambers, Robert and Deryke Belshaw, 1973 "Managing Rural

Development: Lessons and Methods from Eastern Africa”, IDS Discussion Paper no. 15, IDS Sussex, 1973

(revised and forthcoming as Robert Chambers, Managing Rural Development: Ideas and Experience from Eastern Africa,

Scandinavian Institute of African Studies, Uppsala)

Chege, Michael, 1973* "Systems Management and the Plan

Implementation Process in Kenya", Discussion Paper no. 179, IDS Nairobi (* "November 1972" on the paper but from internal evidence this must be 1973)

IDS Nairobi, 1972 “An Overall Evaluation of the Special Rural Development Programme 1972', IDS Nairobi

Kulp, Earl M., 1970 Rural Development Planning: Systems Analysis and Working Method, Praeger, New York

Heyer Judith, Dunstan Ireri and Jon Moris, 1971 Rural Development in Kenya, East African Publishing House, Nairobi

Leach, J.W., 1974 “The Kenya Special Rural Development Programme", Journal of Administration Overseas, vol. 13, no. 2, April

Nellis, J.R., 1973 “The Administration of Rural Development in Kenya", East Africa Journal, vol. 9, no. 3, March. 